DOI:

10.1038/nrmicro1422

\section{URLs}

Magnaporthe grisea http://www.ncbi.nlm. nih.gov/entrez/query. fcgi?db=genomeprj $\& \mathrm{cmd}=$ Retrieve\&do $\mathrm{pt}=$ Overview\&list_ uids $=9583$

\section{Saccharomyces cer-} evisiae http://www.ncbi.nlm. nih.gov/entrez/query. $\mathrm{fcgi}$ ? $\mathrm{db}=$ genomeprj \&cmd=Retrieve \&do $\mathrm{pt}=$ Overview\&list_ uids $=9518$

FUNGAL PATHOGENESIS

\title{
Understanding rice blast disease
}

One of the mechanisms by which plant pathogens cause disease is the delivery of proteins directly into plant cells, where these proteins can promote plant-tissue colonization and suppress plant defences. Mechanisms that bacterial phytopathogens use to effect this delivery are known, but it has been unclear how fungal phytopathogens do so. Now, research published in Nature shows that the P-type ATPase Apt 2 is required for tissue colonization and for efficient delivery of virulence-associated proteins by the fungus Magnaporthe grisea, the causative agent of rice blast disease.

The $M$. grisea genome encodes many secreted proteins, which could be involved in suppression of host defence, so Talbot and colleagues set out to study the mechanisms by which these proteins are secreted. The M. grisea genome was found to contain four genes that putatively encode aminophospholipid translocases (APTs), enzymes that are involved in membrane-fusion events during intracellular protein trafficking. One of these - APT2 — is closely related to the DRS2 gene family of APTs in the yeast Saccharomyces cerevisiae, and members of this family are necessary for efficient Golgi function and are involved in the endocytic and exocytic trafficking pathways. Complementation of yeast mutants with APT2 confirmed that Apt2 fulfils some of the functions of a Drs2-family protein. Furthermore, deletion of APT2 significantly impaired the ability of $M$. grisea to cause rice blast disease, owing to reduced infection of plant roots and leaves. This was shown to be associated with a reduction in exocytosis, because APT2 deletion mutants accumulated abnormal membrane-bound structures in the cytoplasm and could not secrete various enzymes. In addition, inoculation of plant leaves with these mutants elicited reduced plant-defence responses, indicating that Apt 2 might be required for the secretion of proteins that are recognized by the host during a resistance response.

Identification of Apt2 as a fungal factor that is required for exocytosis during plant-tissue colonization contributes to our understanding of fungal pathogenicity. It also has implications for the control of rice blast disease, because proteins that are involved in infection could be targets for the development of new fungicides.

Davina Dadley-Moore

ORIGINAL RESEARCH PAPER Gilbert, M. J., Thornton, C. R., Wakley, G. E. \& Talbot, N. J. A P type ATPase required for rice blast disease and induction of host resistance. Nature 440, 535-539 (2006) 